\title{
The expression of a $V p 1$-like gene and seed dormancy in Mesembryanthemum crystallinum.
}

\author{
Toshiyuki Fukuhara ${ }^{1,4}$ and Hans J. Bohnert ${ }^{1,2,3}$ \\ Departments of Biochemistry ${ }^{1}$, Molecular and Cellular Biology ${ }^{2}$ and Plant Sciences ${ }^{3}$, The University \\ of Arizona, Biosciences West, Tucson, AZ, 85721-0088, U.S.A. \\ ${ }^{4}$ permanent address: Laboratory of Molecular and Cellular Biology, Tokyo University \\ of Agriculture \& Technology, Saiwaicho 3-5-8, Fuchu, Tokyo 183-8509, Japan.
}

(Received 22 May 2000, accepted 7 September 2000)

\begin{abstract}
Seeds of the common ice plant (Mesembryanthemum crystallinum) germinate in distinct sub-populations over a time period of more than 4 weeks following imbibition. Distinguishing early (E)- and late (L)-germinating seeds is the expression of a homologue of the transcriptional activator VP1. The deduced amino acid sequence of ice plant VP1 (MVP1) is 39\% identical (50\% similar) to the sequence of the Arabidopsis VP1 homologue, ABI3. The amount of Mvp1 mRNA, transcribed from a single gene, is different in $\mathrm{E}$ and $\mathrm{L}$ seeds after water uptake. The levels of the Mvp 1 transcripts are very low in immature and mature seeds and they increased during 6 days of imbibition. This expression profile of $M v p 1$ is different from known $V p 1 / A B I 3$-like genes in other plants. Cycloheximide (at $35 \mu \mathrm{M})$ abolishes the increase of $M v p 1$, and L seeds are turned into E seeds, which develop normally when the inhibitor is applied for a short time during imbibition. E seeds treated for the same time period are developmentally impaired and show no radicle elongation. We suggest that the presence and late disappearance of Mvp1 in L seeds is responsible for dormancy and after-ripening of late-germinating ice plant seeds.
\end{abstract}

\section{INTRODUCTION}

Dormancy after seed maturation is typically broken when seeds are imbibed, but imbibed seeds or embryos in a number of species remain dormant for extended time periods (Simpson 1990). Dormancy and the capacity for "after-ripening", the gradual breaking of dormancy by environmental agents, are heritable developmental processes, which include and depend on the synthesis of RNA and specific proteins. The programs are distinct from those controlling seed maturation and germination (Bewley and Black 1994, Goldmark et al., 1992). The mechanisms for maintenance and termination of dormancy are not known in detail, but several approaches have recently brought progress, mainly through the study of genes that are active in dormant seeds. Expression studies have been used to trace the appearance and disappearance of transcripts in dormant seeds or embryos and to follow their fate during after-ripening (Dyer 1993, Goldmark et al., 1992, Johnson et al., 1995, Li and Foley 1995) and biochemical studies have been performed that traced fructose-2,6-bisphosphate in dormant seeds

Edited by Kiyotaka Okada

* Corresponding author. E-mail: fuku@cc.tuat.ac.jp
(Larondelle et al., 1987). Mutants of Arabidopsis thaliana with altered seed dormancy have been obtained (LeonKloosterziel et al., 1996).

In Mesembryanthemum crystallinum (common ice plant) each seed capsule contains approximately 150 seeds. These seeds are not uniform: lightly colored seeds abound in the tip of the capsule followed by increasingly darker pigmented seeds towards the base. This gradient is correlated with dormancy. Seeds with light coloration, which are shed first, germinate immediately after imbibition, i.e., approximately $80 \%$ within two days, and subpopulations of pigmented seeds germinate later, with an average $50 \%$ germination within 10 to12 days. A small population of seeds may germinate only after 30 to 40 days (Fukuhara et al., 1999). Since dormancy and uneven germination pose problems during screening of EMS-generated mutant populations, we were interested in studying the basis of the dormancy phenotype.

Dormant seeds of $M$. crystallinum are characterized by increased expression of $M v p 1$, encoding the ice plant homologue of the transcriptional activator VP1. This is different from observations in A. thaliana, corn and rice, where $V p 1$ transcripts are associated with seed maturation and are low or not detectable in germinating seeds (Giraudat et al., 1992, Hattori et al., 1994, McCarty et al., 
1991, Parcy et al., 1994). In contrast to the dormant seeds, Mvp1 transcripts disappear from early-germinating seeds within a few days following imbibition but persists longer in late-germinating seeds (Fukuhara et al., 1999). Here, we characterize the ice plant Mvp1 transcript. A similar observation has been made about factors distinguishing dormancy types in oats (Jones et al., 1997), indicating that VP1 homologues operate very similar in monocots and dicots. We suggest the existence of a regulatory program that leads to enhanced $M v p 1$ transcription and maintains dormancy irrespective of water uptake by late-germinating seeds.

\section{MATERIALS AND METHODS}

Seeds and plant materials. Lightly colored early-germinating (E) and pigmented late-germinating seeds (L) were separated under a dissecting microscope. Seeds were imbibed on water-saturated paper in a growth chamber $\left(22^{\circ} \mathrm{C}, 12 \mathrm{~h}\right.$ light/ dark cycle).

Gene cloning. Total RNA was obtained from 6 day-old (from imbibition) seedlings using the acid guanidiniumthiocyanate-phenol-chloroform procedure (Chomzynski and Sacchi 1987). The RNA was converted into cDNA with SuperScript II reverse transcriptase (Gibco/BRL). cDNA was subjected to PCR $\left(94^{\circ} \mathrm{C}\right.$ for 1 min followed by 45 cycles of $94^{\circ} \mathrm{C}$ for $30 \mathrm{~s}, 45^{\circ} \mathrm{C}$ for $30 \mathrm{~s}$ and $72^{\circ} \mathrm{C}$ for 1 min). Primers used for the PCR were GCAAGVAARMGIATGGC and WAYCTRTASCGCATGTTCCA ( $\mathrm{I}=$ inosine, $\mathrm{M}=\mathrm{A}+\mathrm{C}, \mathrm{R}=\mathrm{A}+\mathrm{G}, \mathrm{S}=\mathrm{C}+\mathrm{G}, \mathrm{V}=\mathrm{A}+\mathrm{C}+\mathrm{G}, \mathrm{W}=\mathrm{A}+\mathrm{T}$ and $\mathrm{Y}=\mathrm{C}+\mathrm{T}$ ) corresponding to the conserved motifs (ARKKRMA and WNMRYRF, respectively) of the VP1/ABI3 related gene products (maize (McCarty et al., 1991), A. thaliana (Giraudat et al., 1992), rice (Hattori et al., 1994) and Phaseolus vulgaris (Bobb et al., 1995)). PCR products were excised from agarose gels and cloned into the pCRII vector (InvitroGene, San Diego). The 3' region of the gene was cloned by 3' RACE using a gene-specific primer and an oligo(dT) primer (Innis et al., 1990). The 5' region of the gene was cloned by inverse-PCR using genomic DNA as a template for PCR (Innis et al., 1990), because all VP1/ ABI3 genes reported so far contained no intron within their 5' regions. Inserts of RT-PCR and inverse-PCR clones were sequenced at the University of Arizona DNA sequencing facility. The nucleotide sequence of $M v p 1$ has been deposited (DDBJ; AB015183).

DNA and RNA hybridizations. Total genomic DNA from 2-week-old (from imbibition) seedlings of ice plant was purified by the cetyl-trimethylammonium bromide (CTAB) method (Rogers and Bendich 1988) and digested with each of four restriction endonucleases $(B a m \mathrm{HI}$, EcoRI, HindIII or $X b a \mathrm{I})$. Five $\mu \mathrm{g}$ of each digested DNA were subjected to electrophoresis in a $1.0 \%$ agarose gel in
Tris-acetate buffer ( $\mathrm{pH}$ 8.0), $1 \mathrm{mM}$ EDTA and $500 \mathrm{ng} / \mathrm{ml}$ ethidium bromide. Five $\mu \mathrm{g}$ of each total RNA were fractionated in $1.2 \%$ agarose gels in $20 \mathrm{mM}$ MOPS ( $\mathrm{pH} 7.0$ ), 5 $\mathrm{mM}$ sodium acetate, $2 \mathrm{mM}$ EDTA, $0.66 \mathrm{M}$ formaldehyde, and $500 \mathrm{ng} / \mathrm{ml}$ ethidium bromide. DNA fragments or RNA were transferred to a nylon membrane (Zeta-Probe, BioRad) by capillary transfer. Radiolabeled probes were prepared from the RT-PCR clones with $\left[\alpha-{ }^{32} \mathrm{P}\right] \mathrm{dCTP}$ and $\left[\alpha{ }^{32} \mathrm{P}\right] \mathrm{dATP}$ by random primer labeling (Feinberg and Vogelstein 1983). Hybridizations were carried out in hybridization medium $(0.25 \mathrm{M}$ sodium phosphate [pH 7.2], $1 \mathrm{mM}$ EDTA, 7\% SDS, 1\% BSA, 1\% Nonidet P-40 and 0.05 $\mathrm{mg} / \mathrm{ml}$ denatured salmon sperm DNA) for $16 \mathrm{~h}$ at 65 ${ }^{\circ} \mathrm{C}$. Membranes were washed twice for $30 \mathrm{~min}$ each with $20 \mathrm{mM}$ sodium phosphate buffer ( $\mathrm{pH} 7.2$ ) containing $5 \%$ SDS and washed twice again for 30 min each with buffer containing $1 \% \mathrm{SDS}$ at $65^{\circ} \mathrm{C}$.

Phylogenetic analysis. Amino acid sequences of Vp1/ ABI3-related gene products were aligned by using the ClustalX Ver. 1.6 program (Thompson et al., 1997) and percentage of amino acid identity between the proteins were calculated by the GENEDOC Ver. 2.1 program (Nicholas and Nicholas, 1997).

Inhibitor experiments. The following metabolites and inhibitors were used: ABA (10 and $50 \mu \mathrm{M})$, GA3 $(100 \mu \mathrm{M})$, 2,4-dichlorophenoxyacetic acids $(2,4-\mathrm{D}, 1 \mu \mathrm{M})$, cycloheximide $(35 \mu \mathrm{M})$, W7 (a calmodulin antagonist, $50 \mu \mathrm{M}$ ), okadaic acid (250 nM), FK506 (an inhibitor of protein phosphatase $2 \mathrm{~B}, 1 \mu \mathrm{M})$. The substances dissolved in water were present during imbibition for $12 \mathrm{~h}$ to $48 \mathrm{~h}$ in different experiments. After rinsing the seeds with water, seeds were placed on moist filter paper for continued germination.

\section{RESULTS AND DISCUSSION}

This work started from an observation indicating different classes of seeds in a single seed capsule of the common ice plant (M. crystallinum) (Fukuhara et al., 1999). We observed seeds that were lightly colored by betalaines and these seeds germinated early (E seeds), often within the first day following imbibition. Sub-populations show darker betalaine coloration, and these germinated later, with some seeds germinating only 30 to 40 days after they became in contact with water ( $\mathrm{L}$ seeds). Within single seed capsules, we observed stratification, with higher numbers of lightly colored, early germinating seeds towards the tip of the capsule, while seeds at the base were increasingly more pigmented. The latter invariably germinated late (Fukuhara et al., 1999). We were interested in searching for genes that distinguished the two phenotypes. By RT-PCR, we obtained several transcripts indicative of cell divisions, cell cycle control and water 


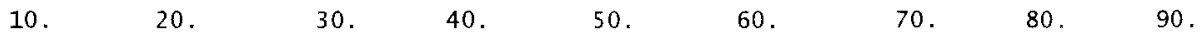

MVP1 MKTEIKDA---ELHGDD-IQGFDALYQHHHQ-QQQPKEEIWFQD---DNNNHHHHQNDAAATNLLDVGDMDVSDPSSLFYAADDFPALPDFPCMS ATABI3 MKSLHVAANAGDLAEDCGILGGDADDTVLMDGIDEVGREIWLDDHGGDNNHVHGHQDD-------DLIVHHDPSIFYG--DLPTLPDFPCMS OSVP1 MDASAGSS-APHSHGNPGKQGGGGGGGGGRG--KAPAAEIRGEAAR- - ...

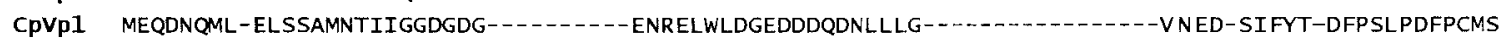

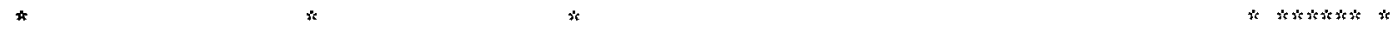

MVP1 SSSSSSSAPAPKKPFASTATSSSASTATSSSWVADHEPSSSTAVSMDLVAPPPPQ-QSGGGGAGGEMGSMS-VDDVDQCMDMMENFGCIDLLESATABI3 SSSSSSTSPAPVNAIVSSASSSSAASSSTS---S---AASWAILRSDGEDPTPNQNQYASGNCDDSSGALQSTASMEIPLDSSQGFGCGEG---OSVP1 SPSSSTFS-SS----SSSNSSSAFTTAAGG--_-_-_-_GCGGEPSEPAS-AADG-----FGELA----DIDQLLD----LASL-.-.-CPVP1 SSSSSSSNPKP---IVSATTSSSAASSSWAA--_-_-_-_-_AMKSETAAAIS-STASMEVQAPATLS----DLDCCIDAMENFGYMDLIDVN $* * * * \quad * * * * *$ (S\&T)

200. 250.

MVP1 ---GDICWDPSPLFGDGDGDESRQLLEEQQLERERERVEEEERAFEEFMLQGGESDSWNVDDVVAGGNSNLDNTSNNNSKQQEHEQQHEQQGLV ATABI3 ---GGDCIDMMETFGYMDLLDSNEFFDTSAIFSQDDDTQNPNLMDQTL-ERQEDQWVPMMENNSGGDMQMMNSS------.--L EQD---

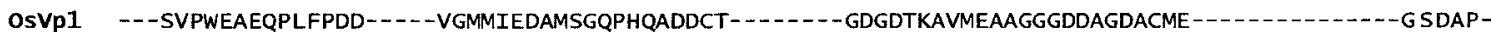

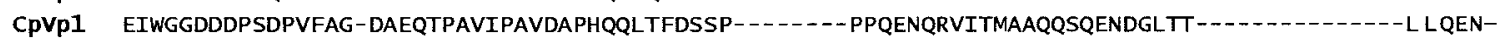
300 . 350 .

MVP1 SSDDLAMVFFEWLKTNKEAISAEDLRNIKIKKSTIEAAAKRLGGGKEGMKQLLKLILQWVQNHHLHNKRESSTVSNNTCGAPVALVDQDHTNSTN ATABI3 --DDLAAVFLEWLKNNKETVSAEDLRKVKIKKATIESAARRLGGGKEAMKQLLKLILEWVQTNHLQRRRTTTTTTN---.---LSYQQSFQ--OSVP1 --DDLPAFFMEWLTSNREYISADDLRSIRLRRSTIEAAAARLGGGRQGTMQLLKLILTWVQNHHLQKKR-P-RT--.------AIDDGAAS--CPVp1 --SELAVIFFEWLKQNKDNISAEDMRSIKLRRSTIDNASKRLGSSKEGKIKLLKLILGWVEQCQLQKKK----TN--------KVGGENSS---

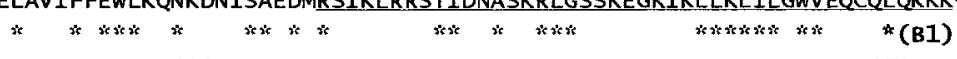
400.

450.

MVP1 NNNDNNNSIIADPNPNPNPNPTPPPLEQQASTTSSCFTTPPP-ATWLPAP-QPQP-FVGDP-AAMVPAP----PPMVGYMGSDPYSAGMAAYPPA ALABI3 --QDP-FQ-----NPNPNNNNLIPPSDQ------TCFS----PSTWVPPPPQQQA-FVSDPGFGYMPAPNY--PPQPEFL---PLLESPPSWPPP OSVP1 --SDPQLP-----SPGANPGYEFPSGGQ------EMGSAA-ATSWMPY--QAFTPPAAYGGDAMYPGAAGPFPFQQSCSKSSWWSSQPFSPPT CPVP1 --QEISNS----DPNQNPSHNFPYNPD-----CCFSTPPPPTPWLPPPPQETPAPASFPASYPQPPPMPMYPYDPYVNTVHHQIPPIPYPPPF

$* * *$ * 550. 500.

MVP1 DYHQMMDPHSW-----AQTPSMQFGMGPQYGS-FPDPSHAAQFGGYPAPYPGFYYHPGPGETAGLMRLGSSATKEARKKRMARQRRFFTHHHR ATABI3 --..--PQS------GPMPHQQFPMPPTSQYNQFGDPTG-FNGYNMNPYQYPYVPAGQMRDQRLLRLCSSATKEARKKRMARQRRFLSHHHR OSVP1 ---AAAAGDMHASGGGNMAWPQ-QFAPFPVSSTSSYTMPSVVPPPFTAGFPGQYSGGH-AMCSPRLAGVEPSSTKEARKKRMARQRRLSCLQQQ CPVP1 VEYPPPPPMMEAQPWAAVAAPPYAVAAQP-QFGAFPEP----NFYACNP-YQMCD----LSGERFVKLGASATKEARKKRMARQRRLYSSHHR

600 . 650.

MVP1 NHNHHQNQNQNNQMNNNLMVEQHGGVGNGNCGVAPHPSPAGNWVYWS-...-.-HPPPLPPQVSHPVGGPPPMVGQMQGLERAAPSGNGFQRQ ATABI3 -HNNNNNNNNNNQQNQTQIGETCAAVAPQLNPVATTAT-GGTWMYWP---------NVPAVPPQL----PPVMETQLPTMDRAGSASAMPRQQ OSVP1 --RSQQLNLS--QIHISGHPQEPSPRAAHSAPVTPSSAGCRSWGIWPPAAQIIQNPLSNKPNPPPATSKQPKPSPEKPKPKPQAAATAGAESLQR CPVP1 -HGHHHHGHQIAPADANSMENHQNGGGDRS-----SPGNSSWMYNNVGAS-------SNVVIQNVDSTQPSSGDKMAAQAQSSNQRLGSNDR (B2)

$$
700 .
$$

*

$$
750 .
$$

MVP1 GGVEKKQGWKSEKNLRFLLQKVLKQSDVGNLGRIVLPKKEAETHLPELEARDGIPIAMEDIGTSRVWNMRYRFWPNNKSRMYLLENTGDFVRSNG ATABI3 VVPDRRQGWKPEKNLRFLLQKVLKQSDVGNLGRIVLPKKEAETHLPELEARDGISLAMEDIGTSR WWNMRYRFWPNNKSRMYLLENTGDFVKTNG OSVP1 STASEKRQAKTDKNLRFLLQKVLKQSDVGSLGRIVLPKKEAEVHLPELKT RDGVSIPMEDIGTSQVWNMRYRFWPNNKSRMYLLENTGDFVRSNE CPVP1 RQQQQQQGLKTEKNLKFLLQKVLKQSDVGSLGRIVLPKKEAEIHLPELETRDGISVAMEDIGTSRVWNMRYRFWPNNKSRMYLLENTGDFVRLNG Whe 800. 850.

MVP1 LQEGDFIVIYSDVKCGKYMIRGVKVR-PQQQGAKAE--TTNKKSCKTQKATABI3 LQEGDFIVIYSDVKCGKYLIRGVKVRQPSGQKPEAPPSSAATKRQNK-........--SQRNINNNSPSANVVV-

OSVP1 LQEGDFIVIYSDIKSGKYLIRGVKVRRAAQEQGNSSGAVGKHKHGSPEKPGVSSNTKPAGAEDGTGGDDSPEAAAAAAAGKADGGGCKGKSPHGV CPVP1 LQEGDFIVIYSDTKCGKYMIRGVKVRPGTKLESKKP---AKKNAR--

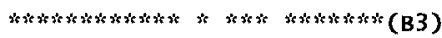

$*$ $* *$

Fig. 1. Sequence comparisons of VP1-related proteins.

The comparison of amino acid sequences of Vp1-related genes includes: MVP1, Mesembryanthemum crystallinum (this work: DDBJ/ EMBL/GenBank share the accession number, AB015183); AtABI3, Arabidopsis thaliana (Giraudat et al., 1992, X68141); OsVp1, Oryza sativa (Hattori et al., 1994, D16640); CpVp1, Craterostigma plantagineum (Chandler and Bartels 1997, AJ000552). Several regions are underlined: rich in serine and threonine (S\&T); regions rich in basic amino acids (B1, B2, B3); NLS - nuclear localization signal. 
uptake, such as those encoding $c d c 2$ and water channel proteins, and studied their expression. While late-germinating seeds took up water and expressed transcripts for water channel proteins, transcripts indicative of cell cycle progression and cell division were expressed much later than in early-germinating seeds (Fukuhara et al., 1999) (and data not shown).

A full-length transcript homologous to the transcriptional activator VP1 was isolated from the ice plant (DDBJ accession: AB015182). The deduced amino acid sequence encoded by Mvp1 (Mesembryanthemum Vp1) was collinear with other VP1 homologues and most similar to that of ABI3 (Fig. 1), the homologue of maize Vp1 (viviparous-1) in A. thaliana (Giraudat et al., 1992, McCarty et al., 1989). Identity scores (Table 1 ) ranged from $39 \%$ in comparison with $A$. thaliana, $34 \%$ for Craterostigma plantagineum (Chandler and Bartels 1997) to $27 \%$ in rice
(Hattori et al., 1994). Similarity, allowing for conserved amino acid changes between the seven VP1 sequences available, was approximately 50\%. The ice plant Vp1 encodes a protein of 790 amino acids, longer than other known VP1, due to insertions in several places between conserved domains. Overall, however, the structure of the ice plant protein is similar to other VP1 (Fig. 1), including a large amino terminal acidic domain with several sub-domains, three basic domains and domains rich in hydroxyl amino acids (Fig. 1; labeled B1, B2, B3, and S\&T, respectively) (Leung and Giraudat 1998). A putative nuclear localization signal (-RKKR-), found in all VP1, is located in a highly conserved region (Fig. 1; NLS). As in other plants, a single gene encodes Mvp1 (Fig. 2), documented by Southern hybridizations after digestions of total DNA with four restriction endonucleases.

VP1 serves as a transcriptional activator involved in

Table 1. Sizes and identity of predicted amino acid sequences between VP1/ABI3-like proteins.

\begin{tabular}{lccccccccc}
\hline \hline & MVP1 & PvALF & AtABI3 & PtABI3 & CpVp1 & C-ABI3 & ZmVp1 & OsVp1 & AfVp1 \\
\hline MVP1 & \multirow{2}{*}{790 aa } & $36 \%$ & $39 \%$ & $39 \%$ & $34 \%$ & $32 \%$ & $28 \%$ & $27 \%$ & $28 \%$ \\
PvALF & & 706 aa & $40 \%$ & $48 \%$ & $32 \%$ & $32 \%$ & $26 \%$ & $25 \%$ & $25 \%$ \\
AtABI3 & & & 720 aa & $46 \%$ & $35 \%$ & $33 \%$ & $28 \%$ & $29 \%$ & $30 \%$ \\
PtABI3 & & & & 736 aa & $35 \%$ & $37 \%$ & $28 \%$ & $28 \%$ & $28 \%$ \\
CpVp1 & & & & 688 aa & $32 \%$ & $30 \%$ & $29 \%$ & $31 \%$ \\
C-ABI3 & & & & & 663 aa & $27 \%$ & $26 \%$ & $27 \%$ \\
ZmVp1 & & & & & & 691 aa & $64 \%$ & $58 \%$ \\
OsVp1 & & & & & & 728 aa \\
AfVp1 & & & & & & & & & \\
\hline
\end{tabular}

MVP1 - Mesembryanthemum crystallinum (accession No. AB015183); PvALF - Phaseolus vulgaris (U28645); AtABI3 Arabidopsis thaliana (X68141); PtABI3 - Populus trichocarpa (AJ003165); CpVp1 - Craterostigma plantagineum (AJ000552); C-ABI3 - Daucas carota (AB005558); ZmVp1 - Zea mays (AJ001635); OsVp1 - Oryza sativa (D16640); AfVp1 - Avena fatua (AJ00140)

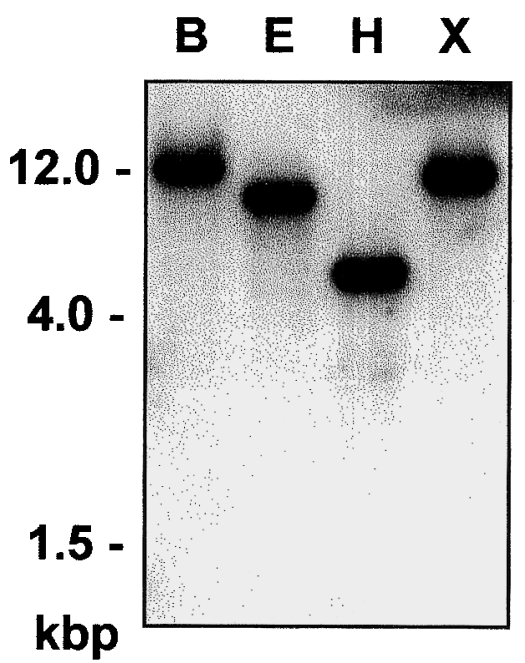

Fig. 2. Mesembryanthemum Mvp1 is encoded by a single-copy gene. Total genomic DNA was digested with BamHI (B), EcoRI (E), HindIII (H) or XbaI (X), followed by size-separation through agarose gel electrophoresis. Hybridization of $V p 1$ was carried out using an RT-PCR clone as the probe.
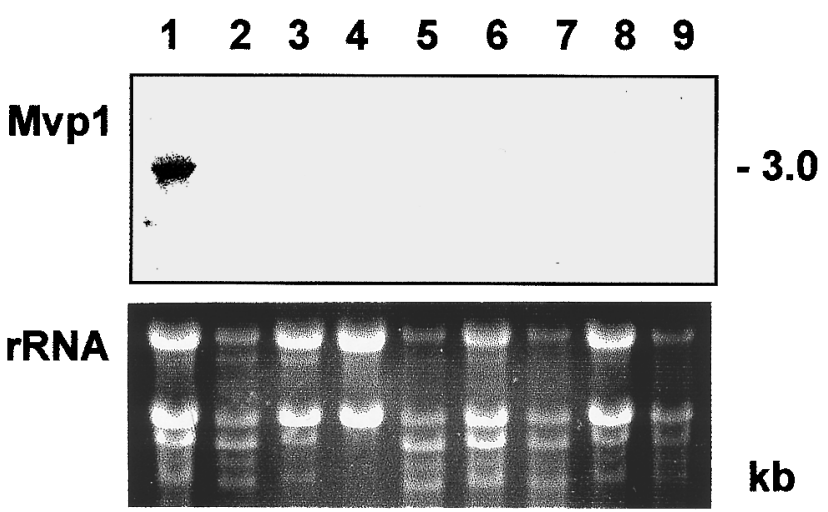

Fig. 3. RNA blot analysis of Mesembryanthemum Mvp1 in various tissues.

Total RNA was isolated from different tissues of $M$. crystallinum and fractionated by denaturing agarose gel electrophoresis. Lane 1, seeds and seedlings imbibed with water for 6 days; Lane 2, leaves (4.5-week-old); Lane 3, leaf meristems (4.5-week-old); Lane 4, roots (4.5-week-old); Lane 5, leaves (7-week-old); Lane 6, leaf meristems (7-week-old); Lane 7, leaves (2.5-month-old); Lane 8, flower meristems and flower buds; Lane 9, flowers. 
seed development and dormancy based on results from maize (McCarty et al., 1989, McCarty et al., 1991), A. thaliana (Giraudat et al., 1992, Parcy et al., 1994) and oats (Jones et al., 1997). VP1 serves in this function most likely in all plants, but the gene and protein has been characterized only in a few species. VP1/ABI3 is expressed throughout seed development, persists for a short time in the germinating cotyledon and hypocotyl, but the transcript is not detectable and not inducible (e.g., by ABA or desiccation) during vegetative growth of $A$. thaliana (Parcy et al., 1994). RNA blot hybridizations were car- ried out with different tissues from the ice plant collected throughout the lifetime of the plant (Fig. 3). A signal for Mvp1 was obtained only from imbibed seeds and seedlings, which contained germinating (E) and dormant (L) seeds. In developing seed capsules and in dry seeds, Mvp1 amounts were even lower and signals from RNA hybridizations were barely detectable (Fig. 4A, lanes IS and MS). Because Mvp1 signals increased for several days after imbibition (Fig. 4A), we hypothesized that early- and late-germinating seed populations might express $M v p 1$ differently. A typical germination experiment included

\section{A}

B
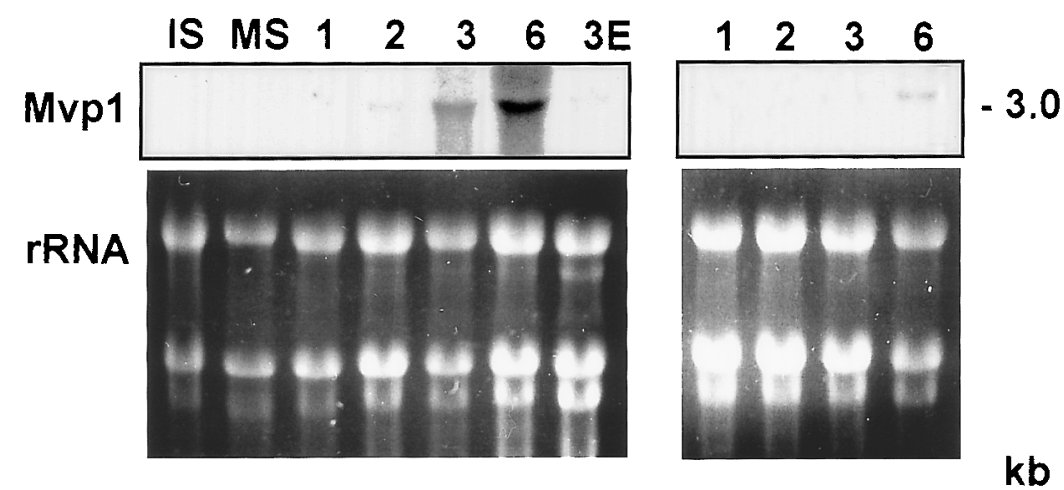

Fig. 4. RNA blot analysis of Mesembryanthemum Mvp1 in seeds and seedlings.

Total RNA was isolated from seeds and seedlings of M. crystallinum, and fractionated by denaturing agarose gel electrophoresis. (A) Lane IS, immature (about one week after flowering) seed capsule; lane MS, mature (dry) seeds; lanes 1-6 seeds and seedlings (combined $\mathrm{L}$ and $\mathrm{E}$ ) imbibed with water for 1, 2, 3, and 6 days; lane 3E, seedlings of $\mathrm{E}$ seeds imbibed with water for 3 days. Weak cross-hybridization is observed with rRNA (top). (B) Seeds and seedlings (combined L and E) were imbibed with $35 \mu \mathrm{M}$ cycloheximide for 2 days, followed by water for 1 day (lane 1), 2 days (lane 2), 3 days (lane 3 ) or 6 days (lane 6).
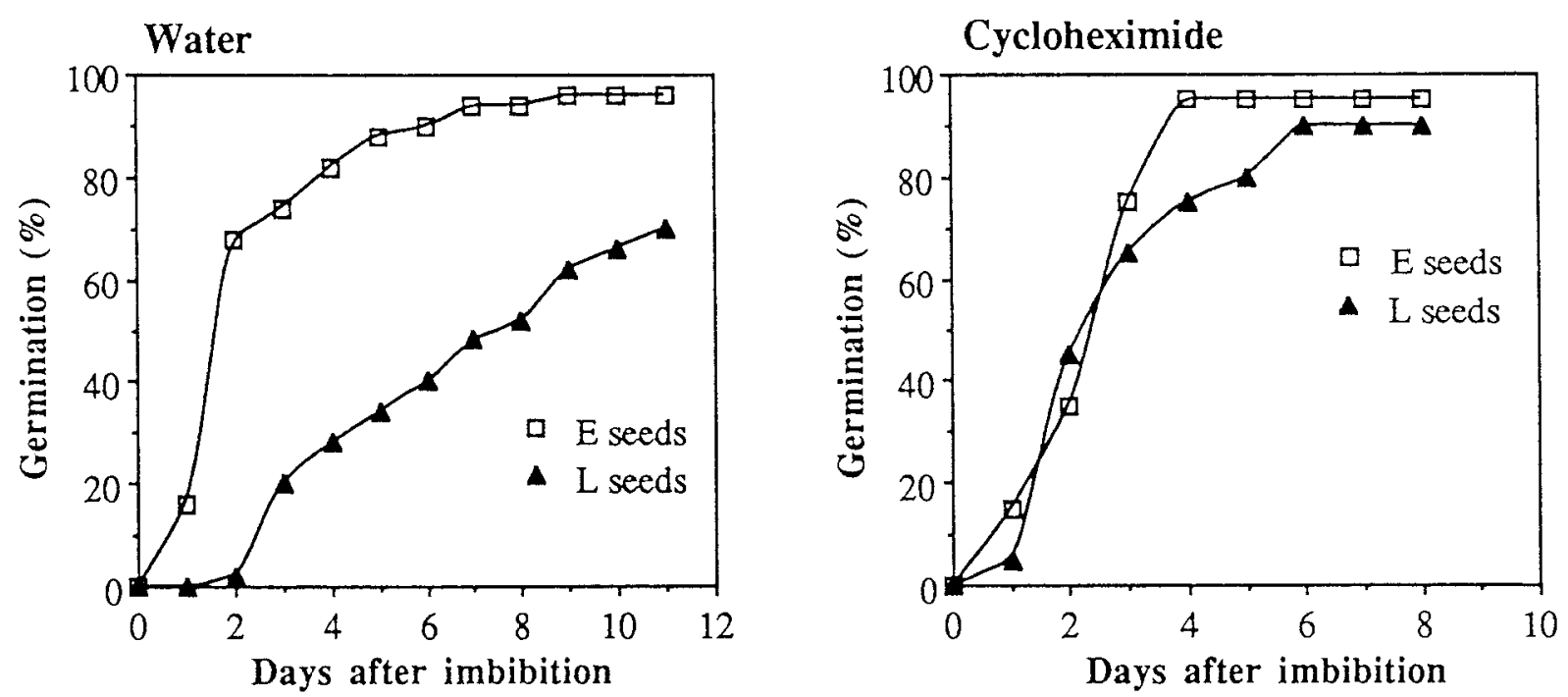

Fig. 5. Germination of $\mathrm{E}$ and L seeds.

Seeds of M. crystallinum were imbibed in water and germination was measured as the time of appearance of the root tip from the seed coat. Water (left), dry seeds were directly imbibed in water; Cycloheximide (right), dry seeds were imbibed in $35 \mu \mathrm{M}$ cycloheximide solution for 2 days and transferred to water. 
approximately 150 each of $\mathrm{E}$ and L seeds, which had been selected according to coloration and size (Fukuhara et al., 1999). Germination rates of $\mathrm{E}$ and L seeds (Fig. 5) confirmed that, indeed, E seeds had germinated to more than $50 \%$ between day one and two after imbibition. A $50 \%$ germination rate for $\mathrm{L}$ seeds, in different experiments, was obtained between day 6 and 10 after imbibition.

Confirming experiments performed in the past (Bewley and Black 1994, Simpson 1990), cycloheximide (CHX) incubation of populations of $\mathrm{E}$ and $\mathrm{L}$ seeds equalized dormancy of the seeds (Fig. 5). L seeds germinated at the same rate as early seeds. In the experiment shown, all seeds had germinated to $50 \%$ by day two when the seeds were pre-incubated for one to two days in $35 \mu \mathrm{M} \mathrm{CHX}$. Results with this inhibitor of protein synthesis document, first, that L seeds are not impermeable to water, and second, that maintenance of dormancy during imbibition requires protein synthesis.

RNA blot hybridizations of the germination process in $\mathrm{L}$ and $\mathrm{E}$ seeds in absence or presence of $\mathrm{CHX}$ revealed a correlation between germination and the amount of $M v p 1$ (Fig. 4). Vp1 transcripts could not be detected in either immature or mature, desiccated seeds (Fig. 4A, lanes IS and MS). In combined E+L seeds, Mvp1 appeared during the imbibition period and peaked approximately 6 days after the seeds were placed on water (Fig. 4A, lanes 1, 2, 3 and 6). During longer periods of imbibition, the Mvp1 signal disappeared gradually (not shown). The increase was due to L seeds alone, because in selected E seeds Mvp1

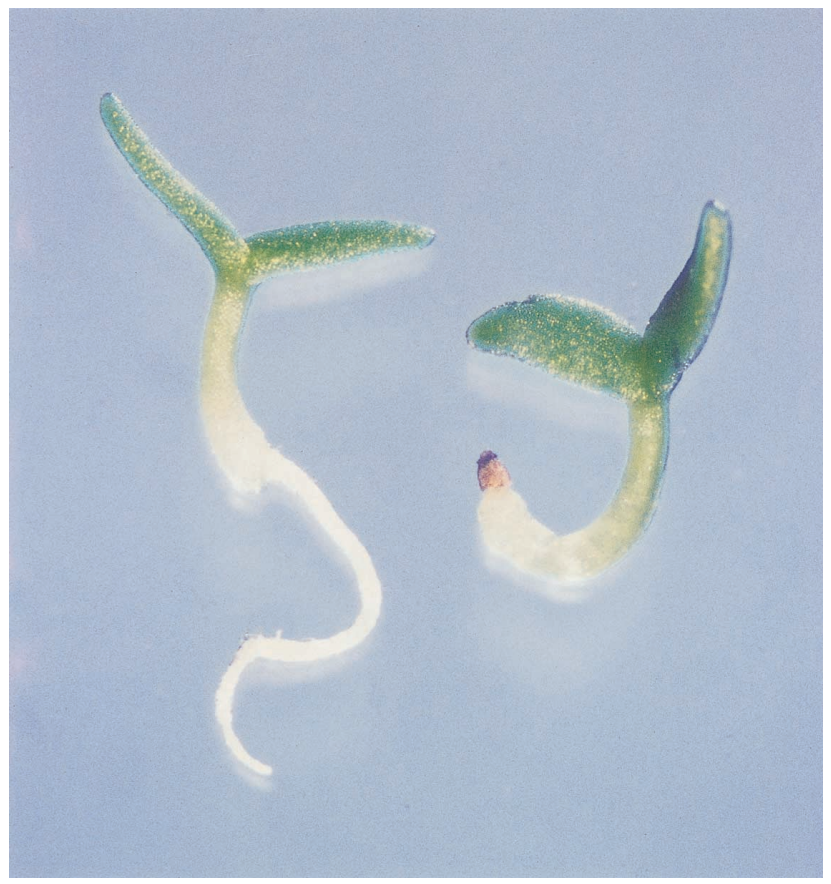

Fig. 6. Effect of cycloheximide to seedling morphology.

$\mathrm{E}$ (right) and L (left) seeds were imbibed with $35 \mu \mathrm{M}$ cycloheximide ( 2 days) and then transferred to water (3 days). remained a very weak signal during germination (Fig. 4A, lane $3 \mathrm{E})$. In general, we estimated the signal strength of Mvp1 in E seeds as at least 10-times lower than in late seeds. Incubation of L seeds with $\mathrm{CHX}$ did not completely reduce the $M v p 1$ signal, but it was, as in E seeds, much reduced compared to untreated L seeds (Fig. 4, compare lanes 6 in panels A and B). This behavior is fundamentally different from that observed for the expression of $V p 1$ in other plants. The $V p 1$-related genes from maize (McCarty et al., 1991), A. thaliana (Parcy et al., 1994), rice (Hattori et al., 1994) and P. vulgaris (Bobb et al., 1995) are expressed predominantly in developing and mature seeds. In these species, $V p 1$ is absent or very low once the seeds started to germinate. It has been reported, however, that the $V p 1$-related gene of carrot $(C-A B I 3)$ is expressed during somatic embryogenesis (Shiota et al., 1998) and $A B I 3$ gene is expressed during vegetative quiescence processes in A. thaliana (Rohde et al., 1999).

Among several chemicals (ABA, GA3, 2,4-D, CHX, W7, okadaic acid, FK506), which were tested for their ability to influence dormancy of either $\mathrm{E}$ or $\mathrm{L}$ seeds, only CHX was effective in breaking dormancy (Fig. 5). ABA did slow germination of E seeds. Neither GA3 nor 2,4-D had any effects on $\mathrm{L}$ or $\mathrm{E}$ seeds and inhibitors of phosphorylation chains involved in signal transduction were equally ineffective in breaking dormancy, although various effects on the germination process could be recorded. Okadaic acid, for example, inhibited the formation of root hairs, and the calmodulin antagonist W7 resulted in a shortening of the hypocotyl and primary root (data not included).

Apart from its effect on Mvp1 expression in L seeds, CHX also influenced early germinating seedlings (Fig. 6). A variable percentage, which depended on the duration of the incubation, of early-germinating seedlings treated with CHX did not develop an elongated radicle. In late-germinating seedlings, this was never observed after a one to two day treatment with CHX (Fig. 6). The most parsimonious explanation is that the E seeds' inability to form a radicle is due to the interruption of protein synthesis by CHX, because E seeds are arrested in a developmental program that follows breaking of dormancy. In contrast, the short treatment of $\mathrm{L}$ seeds with $\mathrm{CHX}$ breaks dormancy, but does not affect the subsequent developmental programs. Consequently, L seeds develop normal roots. If it is the function of MVP1 to maintain L seeds dormant, it is a reasonable assumption that a CHXdependent reduction of $M v p 1$ gene expression would break dormancy. The results confirm observations by others that had indicated maintenance of dormancy as an active process, requiring transcription and protein synthesis (Bewley and Black 1994, Goldmark et al., 1992, Johnson et al., 1995).

We wish to thank Pat Adams, Wendy Chmara, and Jane Dugas for help. T. F. gratefully acknowledges support by the Ministry 
of Education, Science, Sports and Culture of Japan. The work has been supported in part by the Arizona Agricultural Experiment Station and by private funds. T. F. has been on sabbatical leave from Tokyo University of Agriculture and Technology.

\section{REFERENCES}

Bewley, J. D., and Black, M. (1994) Seeds: Physiology of development and germination, $2^{\text {nd }}$ ed., Plenum Press, New York.

Bobb, A. J., Eiben, H. G., and Bustos, M. M. (1995) PvAlf, an embryo-specific acidic transcriptional activator enhances gene expression from phaseolin and phytohemagglutinin promoters. Plant J. 8, 331-343.

Chandler, J. W. and Bartels, D. (1997) Structure and function of the $V p 1$ gene homologue from the resurrection plant Craterostigma plantagineum Hochst. Mol. Gen. Genet. 256, 539-546.

Chomzynski, P., and Sacchi, N. (1987) Single-step method of RNA isolation by acid guanidinium thiocyanate-phenol-chloroform extraction. Anal. Biochem. 162, 156-159.

Dyer, W. E. (1993) Dormancy-associated embryonic mRNAs and proteins in imbibed Avena fatua caryopses. Plant Physiol. 88, 201-211.

Feinberg, A. P., and Vogelstein, B. (1983) A technique for radiolabeling DNA restriction endonuclease fragments to high specific activity. Anal. Biochem. 132, 6-13.

Fukuhara, T., Kirch, H. H., and Bohnert, H. J. (1999) Expression of $V p 1$ and water channel proteins during seed germination. Plant Cell Environ. 22, 417-424.

Giraudat, J., Hauge, B. M., Valon, C., Smalle, J., Parcy, F., and Goodman, H. M. (1992) Isolation of the Arabidopsis ABI3 gene by positional cloning. Plant Cell 4, 1251-1261.

Goldmark, P. J., Curry, J., Morris, C. F., and Walker-Simmons, M.K. (1992) Cloning and expression of an embryo-specific mRNA up-regulated in hydrated dormant seeds. Plant Mol. Biol. 19, 433-441.

Hattori, T., Terada, T., and Hamasuna, S. T. (1994) Sequence and functional analyses of the rice gene homologous to the maize Vp1. Plant Mol. Biol. 24, 805-810.

Innis, M. A., Gelfand, D. H., Sninsky, J. J., and White, T. J. (1990) PCR Protocols: A Guide to Methods and Applications. Academic Press, San Diego.

Johnson, R. R., Cranston, H. J., Chaverra, M. E., and Dyer, W. E. (1995) Characterization of cDNA clones for differentially expressed genes in embryos of dormant and nondormant Avena fatua L. caryopses. Plant Mol. Biol. 28, 113-122.

Jones, H. D., Peters, N. C. B., and Holdsworth, M. J. (1997) Genotype and environment interact to control dormancy and dif- ferential expression of the VIVIPAROUS 1 homologue in embryos of Avena fatua. Plant J. 12, 911-920.

Larondelle, Y., Corbineau, F., Dethier, M., Come, D., and Hers, H.G. (1987) Fructose 2,6-bisphosphate in germinating oat seeds. A biochemical study of seed dormancy. Eur. J. Biochem. 166, 605-610.

Leon-Kloosterziel, K. M., van de Bunt, G. A., Zeevaart, J. A., and Koornneef, M. (1996) Arabidopsis mutants with a reduced seed dormancy. Plant Physiol. 110, 233-240.

Leung, J., and Giraudat, J. (1998) Abscisic acid signal transduction. Annu. Rev. Plant Physiol. Plant Mol. Biol. 49, 199-222.

Li, B., and Foley, M. E. (1995) Cloning and characterization of differentially expressed genes in imbibed dormant and afterripened Avena fatua embryos. Plant Mol. Biol. 29, 823831.

McCarty, D. R., Carson, C. B., Stinard, P. H., and Robertson, D. S. (1989) Molecular analysis of viviparous-1: An abscisic acidinsensitive mutant of maize. Plant Cell 1, 523-532.

McCarty, D. R., Hattori, T., Carson, C. B., Vasil , V., Lazar, M., and Vasil, I.K. (1991) The Viviparous-1 developmental gene of maize encodes a novel transcriptional activator. Cell $\mathbf{6 6}$, $895-905$.

Nicholas, K. B., and Nicholas, H. B. Jr. (1997) GeneDoc: a tool for editing and annotating multiple sequence alignment. (www.cris.com/ $/$ ketchup/genedoc.shtml).

Parcy, F., Valon, C., Raynal, M., Gaubier-Comella, P., Delseny, M., and Giraudat, J. (1994) Regulation of gene expression programs during Arabidopsis seed development: Roles of the ABI3 locus and of endogenous abscisic acid. Plant Cell 6, 1567-1587.

Rogers, S. O., and Bendich, A. J. (1988) Extraction of DNA from plant tissue. In: Plant Molecular Biology Manual (eds. Gelvin, S.B. et al.), pp. A6/1-10. Kluwer Academic Publishers, Dordrecht, Netherlands.

Rohde, A., Van Montagu, M., and Boerjan, W. (1998) The ABSCISIC ACID-INSENSITIVE 3 (ABI3) gene is expressed during vegetative quiescence processes in Arabidopsis. Plant Cell Environ. 22, 261-270.

Shiota, H., Satoh, R., Watabe, K., Harada, H. and Kamada, H. (1998) $C$-ABI, the carrot homologue of the Arabidopsis ABI3, is expressed during both zygotic and somatic embryogenesis and functions in the regulation of embryo-specific ABA-inducible genes. Plant Cell Physiol. 39, 1184-1193.

Simpson, G. M. (1990) Seed dormancy in grasses. Cambridge University Press, Cambridge, UK.

Thompson, J. D., Gibson, T.J., Plewniak, F., Jeanmougin, F., and Higgins, D. G. (1997) The ClustalX windows interface: flexible strategies for multiple sequence alignment aided by quality analysis tools. Nucleic Acids Res. 25, 4876-4882. 